\title{
Smart home modification design strategies for ageing in place: a systematic review
}

\author{
Chuan Ma ${ }^{1}$ (D) Olivia Guerra-Santin ${ }^{1}$ (D) $\cdot$ Masi Mohammadi ${ }^{1}$
}

Received: 16 October 2020 / Accepted: 4 August 2021 / Published online: 27 August 2021

(c) The Author(s) 2021

\begin{abstract}
This research explores current strategies and approaches directed to integrate innovative technologies in the home modification process to support independent living and ageing in place. The systematic review considered studies conducted from the perspective of architecture, smart technology, and gerontology. Scientific databases of related disciplines (e.g. Scopus, Web of Science, Engineer village, Google Scholar, Crossref) were searched and supplemented by hand search method. Thirty-three out of 2594 articles were analysed from three perspectives: the framework of the smart home environment for ageing in place, the smart home modification process, and problems and countermeasures of independent living. The result shows that both home modification and smart technologies can support older adults' independent living, especially with fall prevention and indoor accessibility. Technologies deployed in older adults' homes are transiting from manual assistive technology to more intelligent devices, and the notion of the robotic home has emerged. According to existing practices, universal design is an extensively adopted strategy for smart home design and modification. However, in most cases, universal design is used as a retrofitting guideline for general home settings rather than specifically for smart homes. The fundamental requirements in smart home modification phases are customisation, minimum life interference, and extensible technologies to cope with the ageing process.
\end{abstract}

Keywords Ageing in place $\cdot$ Smart technology $\cdot$ Home modification $\cdot$ Home environment Design strategy

\section{Introduction}

The ageing population is growing rapidly in the Netherlands. By 2050, 26.9\% of the population is projected to be over the age of 65 , and $11.3 \%$ of the population to be over the age of 80 (OECD, 2013). Simultaneously, compared with working-age groups, the number of retired people is growing faster, which puts pressure on limited health resources, and increases the demand for care, services, and medical devices (United Nations, 2019).

Chuan Ma

c.ma@tue.nl

1 Department of the Built Environment, Chair of Smart Architectural Technologies, Eindhoven University of Technology, Eindhoven, The Netherlands 
Therefore, the Dutch government encourages older people to "age in place", defined as remaining living in their own home environment as long as possible (Gobbens \& Van Assen, 2018). The latest data reveal that more than 40,000 Dutch households aged 65 and above are living in an "unsuitable" home environment (de Klerk et al., 2019; Leidelmeijer, 2017). Because of the physical decline of older people, the housing designed for the general population could gradually become uncomfortable or even dangerous. Including the Netherlands, all housing stock in Europe is facing this serious problem, especially for the very old group (over 80 years old) (Braubach \& Power, 2011).

Smart technology has been regarded as a potential solution for providing a supportive living environment for ageing in place (Chabot et al., 2019; Labonnote \& Høyland, 2017; Morris et al., 2014). The word "smart" has recently become an umbrella term for innovative technologies, including partial assistive technologies (AT), ambient intelligence (AmI), ambient assisted living (AAL), Internet of Things (IoT), information and communication technology (ICT), smart home, and artificial intelligence (Marikyan et al., 2019). This paper will use "smart technologies" to refer collectively to these technologies. Generally, smart technologies have four essential functions: entertainment, safety, healthcare and energy-saving (Bouchard et al., 2014; Jaouhari et al., 2019). For older adults living independently, these technologies aim more specifically at enhancing personal safety, health monitoring, living environment control and improving social interaction (Kwok et al., 2016).

The development of smart technologies brings a more detailed classification and selection. Technically, a complete smart home system consists of four components: External device, control system, communication system and the database (Liu et al., 2016; Udupa \& Yellampalli, 2018). Smart home systems are usually classified according to the combination of components. Chief among them are the external devices responsible for receiving information and monitoring. Sensors, as one type of external devices, have hundreds of classifications by functions and use patterns. Thus, the selection of sensors is vital for creating a smart home environment. From the viewpoint of the relation between sensors and housing infrastructure, Ding and her colleagues (2011) determined three main categories: wearable sensors (worn by people), direct environment sensors (distributed in the environment), and infrastructure mediate sensors (installed on the housing infrastructure). Not all external devices of smart systems are required to be embedded in the housing structure (Liu et al., 2016; Reeder et al., 2013), but home modification is still indispensable in eliminating the effects from the surrounding environment and ensuring the device operation effectively. Furthermore, the conditions of most existing home environments are not appropriate to deploy new smart devices (Wong et al., 2017).

Deploying smart technologies into the existing housing stock is a challenge, but only relying on the new technology compatible housing market is unrealistic (Bouchard et al., 2014). There is a growing interest in renovating existing housing stock to cope with the future ageing population. Generally, home modification for older people means alterations of permanent physical features in the home and its surrounding area to facilitate daily tasks, increase comfort, reduce the number of accidents, and support independent living (Iwarsson, 2015; Pynoos et al., 2010). It has been proved as an effective way to prolong older people living in their own homes. Measures include reconstruction of the building structure (building functional improvement), rearrangement of the housing layout (increasing usability and safety of indoor features), and now also contains the installation of smart technology devices (supporting activities and compensating declining functions). The mainstream of existing research pays attention to how smart technologies affect older people's quality of life on domestic features, accessibility, home satisfaction, user-friendliness 
and technological acceptance (Mohammadi, 2008; Rieh, 2018). In most of them, home modification and smart technology were considered as two unrelated interventions but with some overlapping functions. A scoping review by Carnemolla and Bridge (2020) pointed that home modification does not equal smart technology since home modification focuses on the house structure itself. Some blank areas remain in the effects of home modification, for example, the influence of housing typology. A review by Agree (2014) explained the difference between universal design and assistive devices/environmental modifications and suggested taking into account individual capacity to the physical environment. Lee and Kim (2020) highlighted that smart technology should be customised according to changes in people's lifestyles and housing structures. These knowledge gaps related to smart technologies integration and home modification need to be explored in future research.

So far, the real-life smart home projects designed or renovated for older people are limited. In a systematic review, Pal and colleagues (2017) reported that most application scenarios were conducted in ideal environments, such as laboratories or academic institutions. Some researchers avoided mentioning the relation between home modification and smart technologies because this integration requires higher financial cost, more maintenance, and complicating the situation (Rafferty et al., 2017). Thus, the knowledge of combining smart technologies with architectural design is lacking, especially when it comes to retrofitting (Ding et al., 2011; Labonnote \& Høyland, 2017). There is little agreement among designers on smart home design specifications. Dewsbury (2004) suggested achieving a qualitative shift in understanding the translation of needs into architectural design specifications before designing appropriate technology into the home environment.

Along with the increasing number of smart technologies introduced in older adults' homes, the guidelines and standards on technology selection, installation, and application need to be explored. It is important to summarise state-of-the-art theoretical research, laboratory studies, and pilot projects that used advanced technologies to support older people living independently or integrated technologies into the existing housing. Creating smart home environments is an interdisciplinary area, and many different branches of disciplines have put forward research outputs from their expertise. Therefore, a systematic literature review method is used in this research to search related publications, classify involved technologies, and find the relevant experience and results associated with architecture. This review presents elementary design strategies and framework of smart home modification to help better understand the application of architectural and technological interventions in the coming ageing society.

\section{Methods}

\subsection{Search strategy}

The scope of smart home design and modification includes architecture, smart technology, and gerontology. To fully obtain the knowledge from these different fields, a systematic literature search was conducted using interdisciplinary research databases including Scopus, Web of Science, Engineer village, Google Scholar, Crossref and supplemented with the hand search (snowball method). A variety of several synonymous terms for "smart technology", "ageing in place", "home", and "modification" were searched. For example, Table 1 shows the search strategy for Scopus by using Boolean logic. The combinations of these terms were adjusted in different databases according to the various search principles. The 
Table 1 Search strategy for Scopus

\begin{tabular}{|c|c|}
\hline Keywords & Synonyms \\
\hline Smart technology & $\begin{array}{l}\text { "Assistive technology" or "ambient intelligence" or "ambient assisted liv- } \\
\text { ing" or "Internet of Things" or "information and communication technol- } \\
\text { ogy" or "smart home" }\end{array}$ \\
\hline Ageing in place & "Age in place" or "live in place" or "independent living" or "independence" \\
\hline Home & "Housing" or "dwelling" or "residence" \\
\hline Modification & "Refurbishment" or "retrofitting" or "renovation" \\
\hline
\end{tabular}

research period was limited from January 1st, 2010 to December 31st, 2019, for searching the state-of-the-art literature.

\subsection{Inclusion and exclusion criteria}

After removing duplicates, the citations (including grey literature) were screened using the titles and abstracts. The review was restricted to the English language. The included studies focused on applying smart technology in home environments. Hence, the essential exclusion criteria were as follows:

1. Studies were conducted in institutional facilities (nursing homes are outside the scope of this review);

2. Studies focused on the neighbourhood, community or larger scale;

3. Studies were presented as abstracts only;

4. Articles on the same topic from the same author (only include the latest one).

\subsection{Study selection}

Records that met the exclusion criteria were removed after titles and abstracts were scanned. There was no specific age group limitation for study selection because different countries have different "older people" definitions. Moreover, studies focused on frail groups with similar characteristics, such as physical limitations, were also included.

On account of the polysemy of some definitions and keywords (e.g. "architecture" has different meanings in architectural design and computer science), some uncertain studies on technology development and testing were included for the full-text screening.

This review focuses on smart home modification strategies for ageing in place. For selecting the relevant research, full-text screening was required with the exclusion criteria:

1. Studies only focused on medical science or computer science;

2. Studies only focused on wearable technologies;

3. Studies conducted by medical research methods;

4. Studies were not specific for older people or frail groups;

5. No design process, guideline or strategy was provided.

Within the initial 2594 identified records, 126 titles and abstracts were deemed relevant. Of those relevant articles, 77 full-text studies were selected after the exclusion steps, and 28 studies were identified as eligible. The updated search identified an 
additional 29 studies by using the snowball method; 5 of them were selected by the exclusion criteria, resulting in a total of 33 articles and book chapters (Fig. 1).

\subsection{Data extraction and quality assessment}

Data extraction was undertaken by one researcher by using a designed and piloted extraction sheet (see appendix table). Data extraction items included country, contribution category, technologies involved, research tools, research methods, technology application stages, and focuses. A second independent researcher who has expertise on the topic of ageing in place checked the extracted data.

Since the topic reviewed in this research is a relatively new research field, a limited number of studies were fully matched. Therefore, all relevant studies, where even only a part of the contents mentioned "smart home modifications" and "older people", were included. A quality assessment was conducted using the Cochrane Risk and Bias tool. Two researchers assessed the risk of bias independently and then discussed the disagreements, and the third researcher evaluated the result.

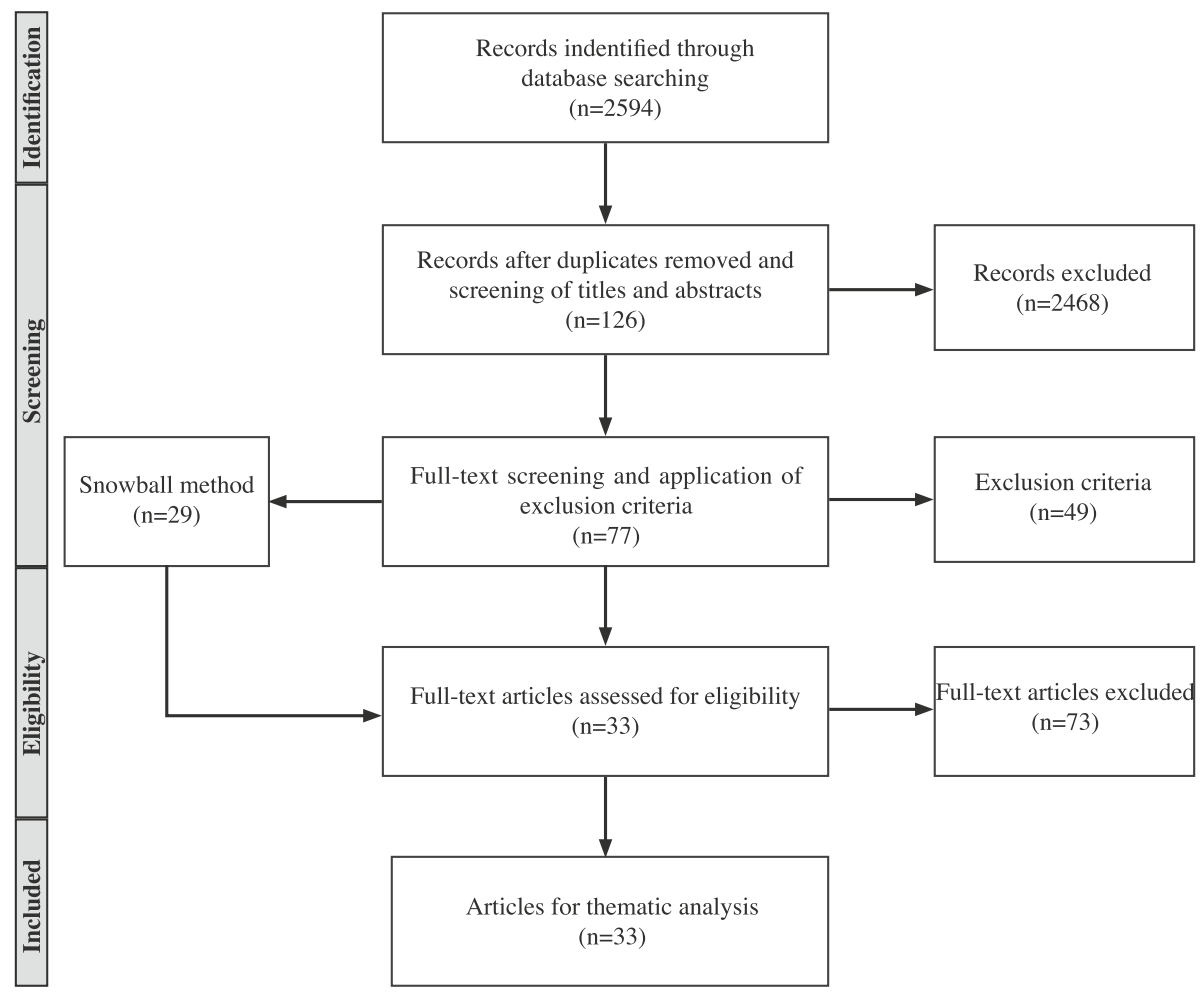

Fig. 1 The literature review process (PRISMA flow chart) 


\subsection{Data synthesis}

A thematic analysis was carried out on the selected studies, which were classified and summarised in three different perspectives of smart home modification: (1) the framework of the smart home environment; (2) the smart home modification process for ageing in place; (3) problems and countermeasures of independent living. The results related to each theme are shown in the following sections.

\section{The framework of the smart home environment: the classification of smart technologies used in the home environment}

This section presents the framework of the smart home environment and illustrates a retrofitted smart home scenario for older people according to technology classifications, functions, and positions (Fig. 2).

Generally designed homes need to be retrofitted for ageing in place. Conventional measures, such as replacing the bathtub with a walk-in shower, can provide a safer living condition. In addition to home modification, devices designed for older people can support their daily activities as well. Non-electronic devices, electronic devices and smart devices (represented with different coloured circles in Fig. 2) are widely used in older adults' homes. These devices or external parts of smart systems are distributed in the home environment.

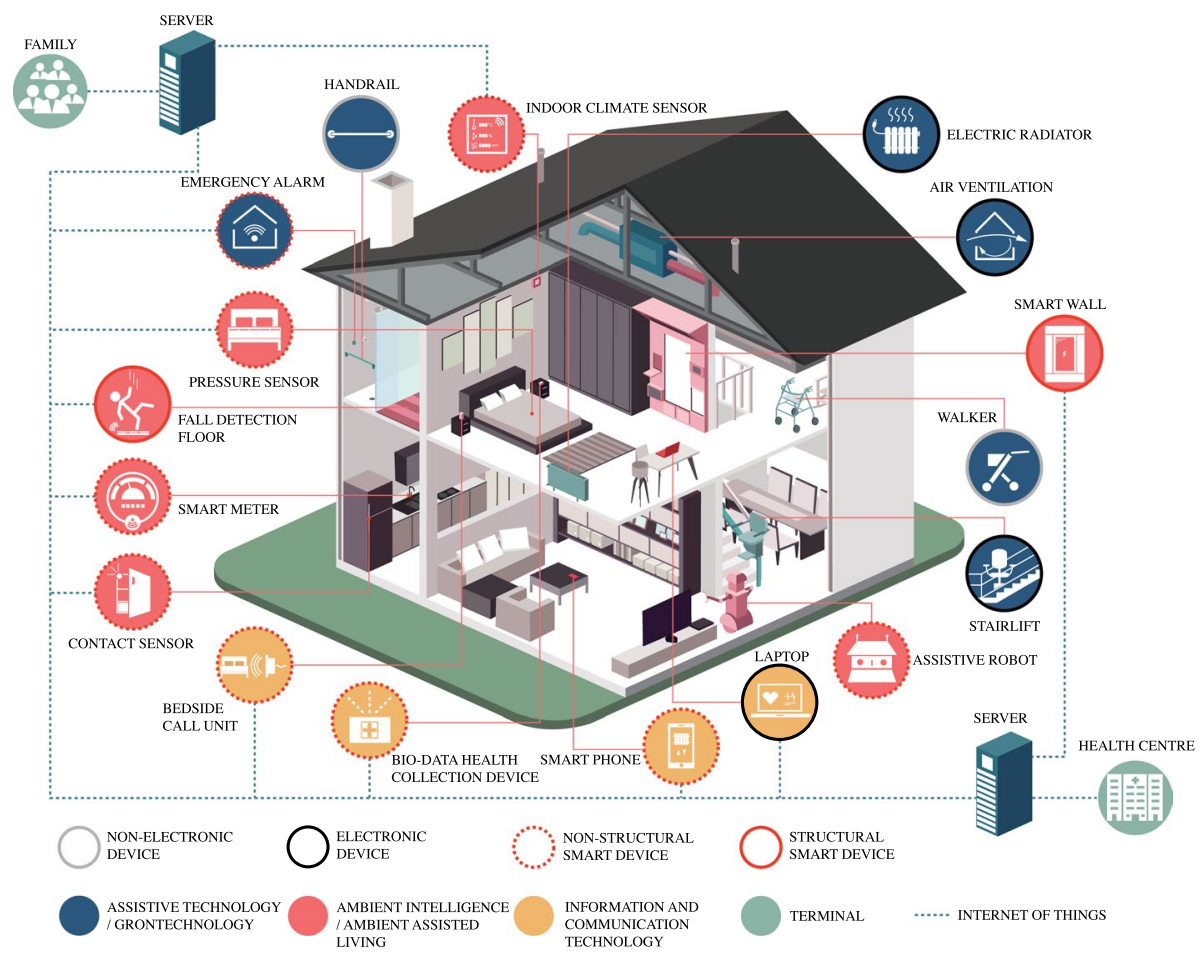

Fig. 2 The classification of smart technologies used in the home environment 
Most of them are non-structural, which are placed on the surface of architectural components or installed inside the infrastructure and furniture, such as indoor climate sensors on walls or ceilings, pressure sensors under mattresses, water meters on taps, and contact sensors on doors (Lê et al., 2012; Ni et al., 2015; Uddin et al., 2018; Visutsak \& Daoudi, 2017). Non-structural technologies make a minimum change of homes and are easier to be deployed. However, structural technologies require retrofitting the existing housing structure for some specific purposes, such as using fall detection floor to replace slippery floor tiles in risky areas to cope with an occasional emergency.

Furthermore, smart technologies have a more detailed classification related to building environment and interactions with users, terminals and other devices. Assistive technology (AT) has the broadest range of meaning, from low-tech gadgetries to complex home automation systems (Gibson et al., 2015). It could be any product or equipment or part of a smart technology package designed to support older people living independently (Beech $\&$ Roberts, 2008). The primary function of AT is to compensate for the decline of older adults' basic living skills and improve the safety of their daily activities. Older people with "architectural disabilities" gradually lose control of their living environment, which can be enhanced by the assistance of AT (McCreadie \& Tinker, 2005). AT can refer to both nonelectronic devices and electronic devices, including smart assistive devices (blue icons in Fig. 2). These technologies or devices designed for older people are also called "gerontechnology". This new term combines gerontology and technology, is an interdisciplinary field of science for creating health, comfort and safe living spaces with supportive technologies (Liu et al., 2016). To this day, AT and gerontechnology are essential equipment in older adults' home and could be transformed from "unsmart" objects to smart devices by integrating innovative technologies.

The developments of information and communication technology (ICT) provides solutions for controlling and managing AT in the home environment through interactive modes, such as computerised devices and communication devices (yellow icons in Fig. 2) (Heart $\&$ Kalderon, 2013). These interactions make technologies easier to be managed by older adults and their caregivers (green icons in Fig. 2). E-health, telecare and more ICT-based technologies offer health care by monitoring and diagnosing older people remotely. Ambient intelligence (AmI) is also an ICT-related concept, in which the home environment consists of user's data-collecting devices, ICT networks and electronic assistive technology (Kerbler, 2014). As a subfield of ambient intelligence, ambient assisted living (AAL) can be defined as an intelligent integration of ICT and sensors into the living environment. It supports the needs of older people through networked technologies in the physical space (red icons in Fig. 2) (Grgurić et al., 2019; Kasugai et al., 2010). AAL has a broader application scope. It can be applied in residential buildings as well as in communities or public buildings ( $\mathrm{Li}$ et al., 2015). Within the field of ageing in place, the concept of the Internet of Things (IoT) is the foundation for transforming physical components used in AAL to smart components and integrating them into living spaces (Konstantinidis et al., 2015). IoT forms local networks by connecting things with remote servers (blue dashed lines in Fig. 2) (Azimi et al., 2017). In other words, the IoT technology does not refer to a specific device but to technical means linking older people, their living environment, and information on their health condition to terminals by the network.

As a result of the emergence and development of innovative technologies, the living environment, technologies, objects, and even people are interconnected. Smart homes can be considered as a more comprehensive concept of smart technologies applied in homes. Including the technologies mentioned above, the definition of the smart home is a special kind of house or apartment equipped with sensors and actuators, integrated into the 
infrastructure of the residence, intended to monitor the context of the inhabitant to improve their experience at home (Demiris et al., 2006; Frisardi \& Imbimbo, 2011). Hui (2017) pointed out that intelligence is an essential ingredient in smart homes. The function of smart homes is developing from primary data collection to a more intelligent interactive care environment.

\section{The smart home modification process for ageing in place}

Smart home modification for ageing in place aims to integrate new technologies through physical environment adjustments to provide an intelligent home. This process usually starts after older people realise that their living environment is unsuitable. The modification consists of four phases: Home assessment, technology selection, design strategy, and user evaluation (Fig. 3). These phases are consistent with the framework proposed by Mohammadi (van Buuren et al., 2019) and Güttler et al. (2015) for designing smart home environments. Their approaches mainly consist of several

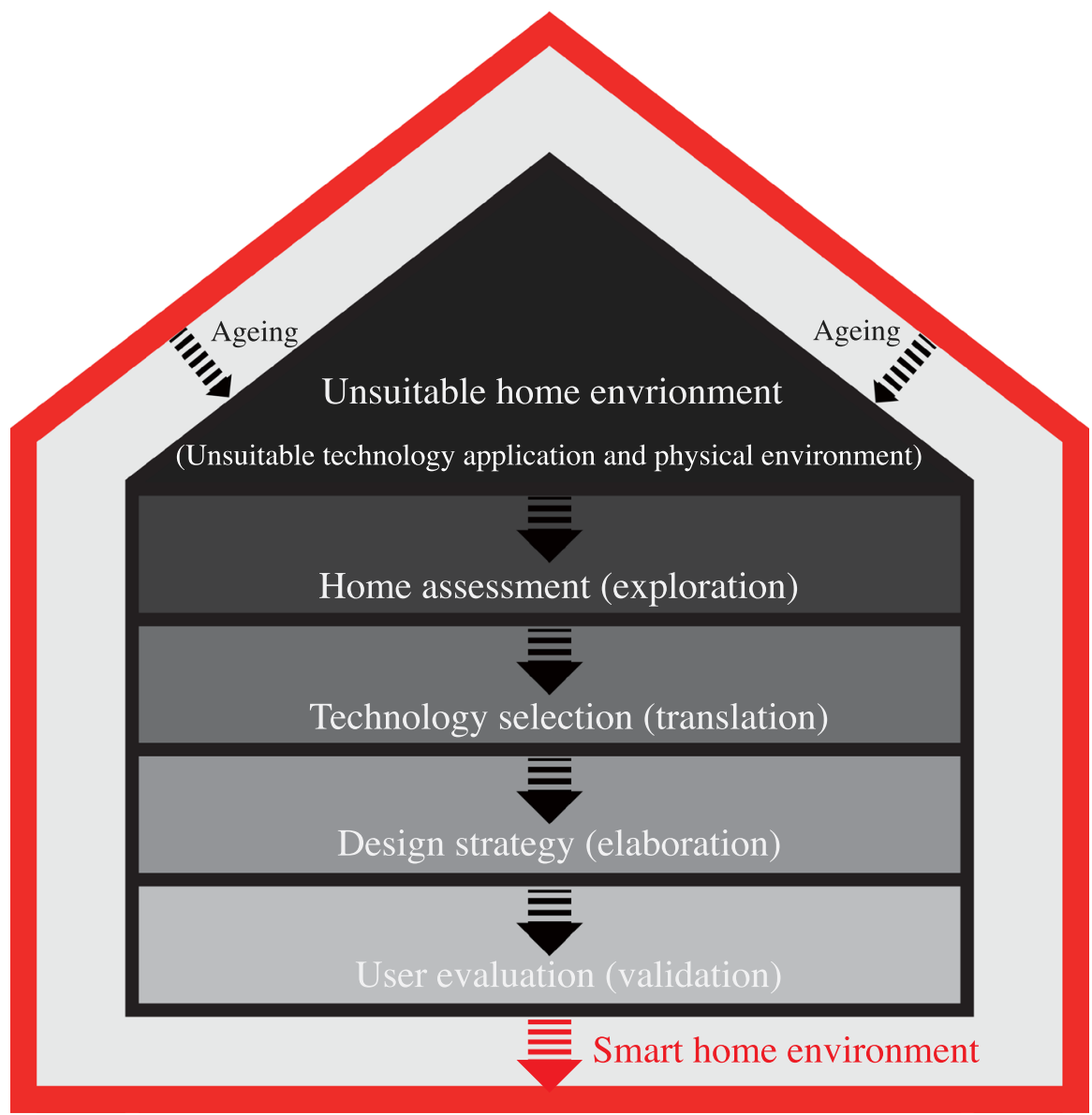

Fig. 3 Smart home modification process 
practical steps: exploring and translating users' requirements, identifying the necessary technologies and processes, building design concepts, experiments in living labs, and producing and validating the final solutions. The use of the participatory design method is highlighted in these approaches.

Ageing is a dynamic process that requires home modification iterations when homes reach the threshold of unsuitable. Therefore, a comprehensive viewpoint is required to understand the opportunities and challenges associated with implementing smart technologies in the home modification process and promoting ageing in place (Engineer et al., 2018). The following sections focus on the steps of the smart home modification.

\subsection{Home assessment}

The home assessment phase is an essential step in smart home modification. Eight studies emphasised its importance of supporting older people living independently (see appendix table). This phase helps identify potential hazards in existing housing stock and contributes to exploring the objective requirements of older people's daily lives. The home assessment is also the foundation for renovation design and construction. Assessment tools vary from traditional checklists to high-tech technologies such as virtual reality techniques. The checklist is the simplest method to detect hidden dangers in homes. The contents of checklists vary according to different objectives. Horowitz et al. (2013) demonstrated the Home Safety Self-Assessment Tool (HSSAT) to diagnose 66 targeted home hazards in the following locations in the home: entrances to the front door and front yard; entrance to back/side doors; hallways/foyers; living room; kitchen; bedroom; bathroom; staircases; and laundry room/basement, and provided potential solutions. Housing Enabler (HE) is another well-established researchbased methodology using checklists for housing accessibility assessment and modification solutions (Haak et al., 2015). However, the main limitation of checklists is that they have been designed for an average target user, ignoring the differences between individuals. The prevalence of Augmented Reality (AR) and Virtual Reality (VR) technologies has overturned traditional methods. These technologies could identify and visualise the harmful indoor features and propose suggestions using a participatory design method in the decision process. Some advanced devices even allow users to experience the simulated scene of retrofitted homes (Lo Bianco et al., 2016; Moussaoui et al., 2012).

Home assessment tools concentrate on three aspects of senior housing: Structural modification (increasing accessibility of indoor spaces), layout adjustment (simplifying tasks of daily activities), and devices application (supporting activities and compensating living abilities) (Braubach \& Power, 2011; Chase et al., 2012). Current studies mainly explored older people's functional decline with the impact of domestic features changes, and involved technologies were usually classified as general housing components. The technological effects on users and their living environments have been ignored. Furthermore, older people's homes are often structurally unsuitable or unprepared for the straightforward installation of smart home systems (Normie, 2011). Therefore, an assessment tool is required to evaluate the compatibility of smart technologies with existing housing structures before modification design and construction. 


\subsection{Technology selection}

As a total heterogeneous group, older people have various and changing living habits, limitations, requirements, and preferences. These differences should always be taken into account in the technology selection phase, which aims to match users' characteristics (Jännes et al., 2015). As McCreadie and Tinker (2005) summarised, the acceptability of smart technologies requires matching both older people's individuals and housing conditions, and it is also affected by the attributes of the technology itself. Therefore, it is crucial to explore compensation requirements in older people's daily lives and translate them as selection criteria to match suitable technologies.

The features of smart technologies with higher acceptance are identified as being less intrusive, having lower costs, being user-friendly control, having a user-friendly interface, and having fewer design features (Chabot et al., 2019; Golant, 2017; Normie, 2011). Agree (2014) advocated for the benefits of using universal design for developing standardised devices and systems to make sure they are uniformly accessible or usable by persons of varying abilities. However, the main barrier for promoting smart technologies in the market is the missing common standards in the interoperability and compatibility of these products (Jännes et al., 2015; Mohammadi, 2010; Normie, 2011; Phan \& Kim, 2020). Challenges remain for older people to constantly adapt to non-universal smart systems until these barriers are eliminated in the future.

\subsection{Design strategy}

Five studies were found focused on integrating innovative technologies into the domestic environment in different stages, from concept to pilot project (see appendix table). Röcker and Ziefle (2011) proposed combining communication and interaction mechanisms as well as bio-signals with basic architectural elements and building structure. People can directly interact with the smart homecare environment, consisting of an interactive wall, a smart floor, and a medical helper device. Linner et al. (2015) developed the concept and prototyped "robotic micro-rooms" (RmRs), which do not require refurbishment of the existing interior. The concept is based on the "terminal-wall" approach that pre-embed assistive devices into modular elements as integrated furniture. Base on the size of the three-dimensional space surrounded by the ceiling panel, wall panels and the floor panel, the adjustable smart components can be easily inserted into existing rooms and enables a "plug-n-play" installation. The integrated robotic devices and furniture such as ceiling robots, robotic cabinets, robotic service walls are also easier to adjust and lower the threshold of older people managing their daily living (Güttler et al., 2015). However, real smart home retrofitting projects need to deal with practical problems. The pilot project of Smart Cottage in McKeesport, Pennsylvania (Behr et al., 2010) tried to use wireless sensor technologies for solving the design problems caused by setting new data channels inside walls of the existing house. This approach aims to keep the aesthetic and neatness of the interior space. Moretti and colleagues (2013) reported their experiences of installing a smart home system in an existing home. To avoid damaging the housing structure, they used a more secure and traditional (iterative) method of mounting selected external devices by creating custommade brackets, photographing the site, drafting design drawings, printing the parts, and checking the fitness. Because interior designs in different homes have little uniformity, this universal customisation approach would normally take longer. 
Nine studies described the challenges of creating smart home environments and offered strategies to gain a higher user acceptance (see appendix table). In a review article, Bitterman and Shach-Pinsly (2015) pointed out the lack of empirical evidence to prove the effectiveness of using smart technologies in home environments. Most studies remained in the laboratory stage. Hence, the universal design, also known as design for all or inclusive design, has been regarded as one of the few guidelines for designing a home environment without architectural barriers (Bamzar, 2019; Gabriel et al., 2014; Kerbler, 2014). In the context of smart home design, universal design has another meaning of commonality in technology design and application. The features of universal designed architectural components and devices are convenient to install, modify or remove and more adaptive to coping with older adults' changing daily lives (Ahrentzen \& Tural, 2015). However, the understanding of seniors' lives is often different between the aged group and young designers. Thus, Iwarsson (2015) suggested that designers negotiate with older people to consider their personal needs and preferences in the design phase instead of proposing generally applicable recommendations.

Compared with the top-down design, user-centred design approaches have been proved to be better strategies to understand the individual experiences of older adults and their requirements (Durick and Leung, 2018). These approaches for designing domestic environments for ageing well come from the Human-Computer Interaction (HCI) and participatory design method. HCI is an effective solution for developing smart technologies and devices from a user-centred perspective. It contributes to understanding the preferences of older adults concerning smart environments by gathering feedback regarding the interaction between older adults and a smart environment (Jacelon \& Hanson, 2013). A series of HCI inspired design guidelines have been presented, such as HCI technology as a visualisation tool to assists older people in anticipating changes to their home environments (Lo Bianco et al., 2015). De Vries and colleagues (2012) developed a design system that storages smart architectural components in a database, including the smart wall, smart kitchen, and smart furniture. Through this system, users can experience smart living in the virtual domestic setting and interact with added technologies. Another study of the Massey University Smart Environment (MUSE) group explored requirements analysis for smart homes and occupants (Lyons et al., 2010). Researchers introduced Use Cases to assist smart home design for older people by the database-documented discussions and behaviours from a wider smart environment community. These user-centred methods are becoming crucial methods for smart home design research, which can increase the technology acceptance and user experience.

\subsection{User evaluation}

Smart technologies cannot completely replace the function of a supportive physical environment; in other words, ageing in place requires both architectural and technological interventions to keep older adults' living quality at home (Carnemolla, 2018). The user evaluation is the phase for validating the effectiveness of these interventions and use users' experience to guide future practices. However, the limitation of this research type is that most of the outcomes are based on self-reports and interviews, lack objective performancebased measures (Cho et al., 2016). Guiding practices need more scientific data to avoid detours in the modification process. The retrofitted home is unlikely to be entirely suitable by only one modification, which means more investment and construction cycles. A 
comprehensive method is needed to analyse the effects of architectural and technological interventions in various types of residential buildings.

In this review, we identified seven research projects where recognised systems for evaluating the modified living environment of older people were developed or tested (see appendix table). Carnemolla (2018) explored her Human/Activity/Space/Technology (HAST) model for ageing in place through three case studies in which smart technologies were introduced into homes of older people and mapped the implications, limitations, and outcomes on the template design. This model evaluated the home environments in four aspects: A person's functional capacity (human), care (activity), the built environment (space), and smart technology (technology). Cho and Kim (2014) proposed a framework of user interface design principles for older people that helps to evaluate the usability of smart devices in their homes. This framework was based on five evaluation tools for living environments: multiphasic environmental assessment protocol (MEAP), nursing unit rating scale (NURS), professional environmental assessment protocol (PEAP), environmental audit tool (EAT) and evaluation of older people's living environments (EVOLVE). The framework was characterised by 12 smart devices: Six interactive properties and six supportive properties. It provides a new method for evaluating the built environment and offers a rational basis for the selection of alternative proposals. In the research "Smart Home Independent Residing" enabled by Intelligent Solutions (IRIS), Ocepek's team (2013) used the Canadian Occupational Performance Measure (COPM) and the Functional Independence Measure (FIM) to evaluate the older people's satisfaction and independence with the assistive technology implementation and home modification. Renaut and colleagues (2015) investigated French residences for seniors through semi-structured interviews. The study focused on how they construct the space in their home environments and how to fit new devices with the evaluated housing condition. They stressed the importance of involving older people in the design and construction phase of home modification and the advantages of small repairs and minor changes. In the Housing and Independent Living (HAIL) study (Mackenzie et al., 2015), six key themes emerged from the semi-structured interviews: housing choice, attachment to place, financial issues, changes to the home over time, transport and anticipating the future. The study investigated what the occupant (over 70 years old) had retrofitted to their homes and the expectations for future modification. It discussed the role of assistive technologies, devices or modifications in the home environment and highlighted the importance of housing design in planning a supportive home environment. Lien and her team (2015) used the ecological theory of ageing (ETA) and selection, optimisation, and compensation (SOC) model as their theoretical frameworks to understand the adaptive environmental behaviours employed to achieve Person-environment (P-E) fit in older adults' homes. The results could be used to develop and optimise current home modification practices. Bishop et al. (2015) reported the first national evaluation of the prevalence of residential assistive devices and modifications among the multiple sclerosis group in America. Although this research is not specific to older people, multiple sclerosis patients are also a relatively vulnerable group. Researchers used a qualitative analysis method and categorised the indoor changes by rooms or areas identified. This method is instrumental for the specific renovation of each room in the domestic environment.

The above studies show the evaluation results of home modification for frail groups and reveal the prevalence of modified or adapted housing in the housing market. Interestingly, the majority of included projects (6/7) were only equipped with unsmart assistive technology as a functional complement to housing facilities. The limited number of study samples is the main reason for this result, and there is no correlation or uniform standard between the evaluated cases. However, the mentioned evaluation tools and 
methods can be references for developing specific smart home modification evaluation systems.

\section{Problems and countermeasures of independent living}

Even healthy older individuals encounter challenges due to normal age-related changes. The functional decline of the body often increases the difficulty of activities of daily living (ADLs) and instrumental activities of daily living (IADLs) (Ravishankar et al., 2015). Restricting older adults' daily activities is impractical. An effective way to support independent living is to detect and erase the hazards in their living environments. Eight reviewed studies focused on the hazards that could influence older people's independent living, specifically on fall prevention and accessibility (see appendix table). A few of them showed the types and extent of home modifications associated with daily activities and the implications of these potential problems on older adults' independence. Although both home modification and smart technology can theoretically enhance independence, the effects and prospects of these interventions in home environments are still being explored.

Falling is one of the most dangerous situations that threaten older people living independently. The common definition of falls is unintentionally coming to impact on the ground, floor, or other lower level (Lamb et al., 2005). Serious consequences may happen after the falls if they fail to get timely treatment. Falls are the leading cause of injury and deaths in people over age 65, and the risk is higher following age. Over $30 \%$ of older adults fall each year (Chase et al., 2012). Most fall-related injuries (55\%) occur inside the home, including falls on stairs and in rooms throughout the house. Hazards of falls are hiding in the domestic environment. $80 \%$ of households contain at least one identifiable hazard, and approximately $40 \%$ of them containing five hazards and more (Carter et al., 2000; Pynoos et al., 2010). The majority of the reviewed studies mentioned the dangers of falls among older people, and five of them investigated how to prevent falls (see appendix table). The measures include improving older adults' body function by strengthening exercise and optimising the indoor environment. For the indoor environment, action should be taken to start with the housing assessment phase. Checklists are widely used to assess the common hazards in the home environment, even though the results are not intuitive. With the advent of AR technology in recent years, these high-tech devices can scan and visualise problem areas and help older people better accept the home modification design (Lo Bianco et al., 2016). Fall risk in daily activities cannot be eliminated, several strategies provided by literature studies for enhancing indoor safety: universal design (reduce indoor barriers, and improve the versatility of structures and spaces to facilitate functional expansion and installation); optional fittings (add architectural components such as handrails, ramps, and stairlifts that protect for the daily activities); co-creation design (create a senior-friendly home environment according to the specific circumstances of occupants); and smart technology (install fall detection sensors and automatic alarm for detecting dangerous situations and calling rescue) (Chabot et al., 2019; Lo Bianco et al., 2015; Pynoos et al., 2010).

Accessibility has a broader definition in the field of smart home research. The scope mainly includes physical accessibility, financial accessibility, technical accessibility, and psychological accessibility (Lê et al., 2012). Physical accessibility is the basic premise of independent living, especially for the older group with mobility limitations. The definition of physical accessibility is usually described as the older people's mobility, reachability, and occupancy in interior spaces or with building components at the architectural design 
level. Many architectural features impact the physical accessibility from structure to small construction detail, including spatial articulation, compactness, available room to manoeuvre, number of floors, and open plan (Van Steenwinkel et al., 2017). With the appliance of assistive devices and smart technologies in the future, the indoor space for devices placement and operation also needs to be taken into account. At present, the research mainstream is the technical accessibility of how older people use smart technology at home and their acceptance of new technologies. Few researchers have tried to investigate the actual physical accessibility of older people in different living scenarios when they have mobility limitations. Moussaoui et al. (2012) proposed experimental research using virtual reality technology for a personalised assessment of the accessibility to a dwelling. They tested the accessibility of mobility, reaching and grasping by modelling a person moved in a wheelchair or with a walker. Using VR technology, they visualised the possible state after modifying the environment and the ability of older adults to control their living spaces. Their research provided an approach to use VR technology as a supplementary method of architectural design. For smart home modification, it is essential to simulate and validate technology application scenarios in the design stage.

\section{Discussion}

\subsection{Summary of findings}

In the last decade, smart technology development boomed and created a prosperous market. The scenario of smart homes that fully support ageing in place is still far from a reality (Helal et al., 2012; Peruzzini \& Germani, 2016). Older people choose to live in smart homes depending on intentions to enhance safety and reduce the demand for care. However, the acceptance of "smart" devices is still lower than expected (Arthanat et al., 2019). Using common assistive technologies to expand housing functions such as grab bars, railings, and stairlifts is still the designers' and users' preference when retrofitting homes for ageing in place. The barriers of smart home modification are high cost, low trust, stigmatisation, maintenance, ethical problems, and many other aspects of smart technology application (Mohammadi, 2010; Robillard et al., 2017; Storey, 2011; Wang et al., 2019; Wong et al., 2017). In this research, we conclude that the following strategies are crucial: (1) consider the integration with the existing home layout, structure and materials before deploying smart technologies; (2) minimise the interference to older adults' original living environment; (3) use extensible technologies and design to reduce the frequency of home modification.

Home modification for ageing in place follows universal design guidelines of installing, removing or renewing building features, which is not extraordinarily expensive or complicated. But adding smart technologies into housing structure will increase the difficulty of the design and construction. Smart technology requires spaces for its installation and operation and changes the indoor environment according to its locations, materials, and appearances (Bitterman \& Shach-Pinsly, 2015). Most studies so far discussed technology application at the theoretical level. However, in realistic home environments, many factors 
are likely to lead to mismatches among technology usage and space usage and deviations between design and application (Allameh and Heidari, 2013). For instance, some light sensors are designed to be embedded in ceilings. However, to keep the neatness of ceilings, users prefer instead to put the sensor on the top of the wardrobe that influences data collection accuracy. Furthermore, different building materials, surface reflectance, and indoor obstacles also affect smart devices' operation, such as reinforced walls, which could cause indoor localisation and signal reception malfunctioning (Labonnote \& Høyland, 2017; Schikhof et al., 2010). Thus, the effects of installing and using new devices sometimes cannot fulfil expectations if the existing home environment is not properly considered.

From the existing literature, unobtrusive smart technologies are more acceptable (Kim et al., 2013; Ravishankar et al., 2015). These technologies support older people ageing in place while maintaining their dignity, privacy, and familiarity. The preference is to integrate the smart technology as an invisible part of the housing (Kim et al., 2013; Linner et al., 2012) instead of highlighting the "smart". If smart technologies are visible, the products themselves or the interior features after the installation should be aesthetically acceptable (Mohammadi, 2010). An opposing view hold by some researchers is that smart technologies can exist in living spaces in a more futuristic way rather than be completely hidden behind the building structure. The concept of "plug-n-play" is a method to simplify the process of technology installation and home modification (Güttler et al., 2015; Linner et al., 2015). There is no conflict between these viewpoints. Both "hiding" and "plugn-play" strategies aim to simplify the modification process and minimise interference to the living environment. The only difference is the integrating degree of technologies and housing condition, which depends on the user's technology acceptance. According to the user's preference, smart home modification requires a consistent strategy from design to implementation.

Ageing is a dynamic process. There is no adaptability concept in the field of smart home design for older people which varies according to users' needs and characteristics (Lê et al., 2012). Helal and Bull (2019) pointed out that to adapt to older adults' changing needs, the integration of smart technology in living spaces should be flexible, adaptive and changeable. With the decline of individuals' abilities, customisable supports (e.g. assistive technologies, home modifications) are also crucial to keep older people's independence as long as possible (Remillard et al., 2019). Therefore, the smart home modification design strategy needs to take into account variables of older people's circumstances and their homes for a long-term plan. Home modification should solve immediate problems and prepare to cope with different situations of future ageing stages. Because it is often late and risky when older people realise they are living in an unsuitable home. Homes renovated by an extensible strategy could be easier to upgrade before reaching "unsuitable" thresholds. Furthermore, along with the smart technology rapid development, it is necessary to reserve spaces for technology upgrading and replacement according to housing characteristics.

\subsection{Limitations}

This research has some limitations. First, although we used a thorough search strategy and expanded the searching scope, only thirty-three studies were identified relevant to this systematic review topic. Smart home modification is a relatively new and interdisciplinary 
field that develops based on practices. The existing smart home projects designed for older people are limited. Less than a quarter of thirty-three studies were in the pilot project stage or involved technologies were widely used (see appendix table). Second, due to the heterogeneity research perspectives of available studies, this research was conducted using the thematic analysis method. Not all included studies were based on architecture research. Technologies in some studies were research tools which not used to support older people's independent living. Third, a growing number of innovative technology terms have emerged in recent years. The high-frequency terms found in existing literature were listed and explained in this review. Fourth, we built a basic design framework of smart home modification, described the smart home scenario and summarised the latest research orientation. The framework needs to be validated with further research and practices.

\subsection{Implications for practice}

Different from traditional architectural design, smart home modification design for older people focuses on the ability compensation. It is user-centred other than concentrating on the building itself. While this review presented the basic design flow, strategies, tools and main design points, there is a need to comprehensively understand and analyse the specific situation of occupants and their living environments. Otherwise, it is difficult to guarantee the effect of home modification. In some cases, the home modification could worsen the situation and negatively impact older people's lives (Thomése \& van Groenou, 2006; Trecartin \& Cummings, 2018).

The diversity of smart technology terms, products, and protocols is another challenge for designers and users. The low technology compatibility and technological fragmentation lead to a low adoption rate and users' confusions (Phan \& Kim, 2020). There is a need to establish a clear and comprehensive classification standard of smart technologies and systems to match their functions to user needs. It could also be helpful to indicate the architectural requirements of technologies (e.g. operation space, building facilities, installation site) as references for the modification design. User-friendly and application-friendly smart technologies are more likely to be used in seniors' homes.

\subsection{Future research}

The reviewed studies were mostly conducted in ideal conditions and only provided theoretical data. Knowledge of the actual effects of smart technology and architectural interventions on older people's health is still missing (Hammink et al., 2019). More practical projects will bring sufficient application data and tangible user experience, reveal design and 
application problems in actual environments that can accelerate smart technology adoption in the housing market.

In the near future, smart technology in the home environment could be more than a part of the architectural element and brings innovation to the architectural industry. The function of smart homes will extend beyond traditional housing. It will interact with users, respond to their requirements and manage their homes. Future studies need to propose different ways to design "intelligent" homes for older adults (Lee \& Kim, 2020), bridging the connections between housing structure, smart technology and occupant.

\section{Conclusion}

This review illustrates the innovative technologies used in the home environment, summarises smart home modification design strategies from recent research, and identifies problems and countermeasures of independent living. At present, there are many categories of innovative technologies that can be applied in older adults' homes. In addition to smart devices, other objects, furniture, and even infrastructure in the home environment can be connected as a part of the smart home to support daily lives. Based on user-centred design approaches, these supportive technologies can be selected and appropriately deployed in homes. Universal design is an essential design strategy to eliminate the environmental and technical barrier of a smart home environment. But due to the diversity of individuals and heterogeneity of housing, universal design cannot be entirely applied to the process of housing assessment, technology selection, integration design, and user evaluation. To achieve ageing in place, a customise modification scheme and an extensible living environment are required to keep fitting older people's needs and maximise the effectiveness of smart technology. The approaches of designing and renovating smart homes still need to be explored in future interdisciplinary research and verified in real-life projects.

\section{Appendix 1}

See Table2. 


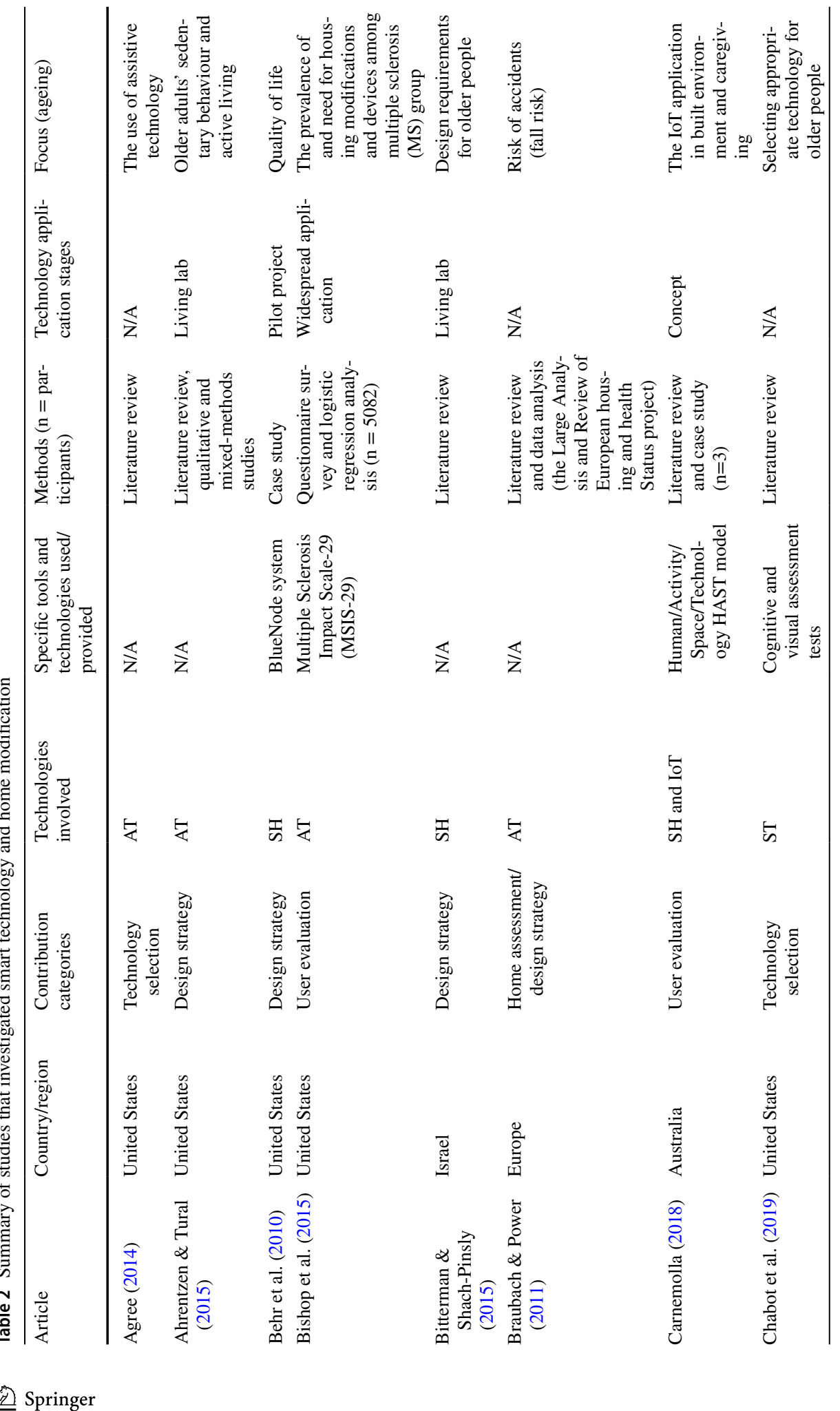




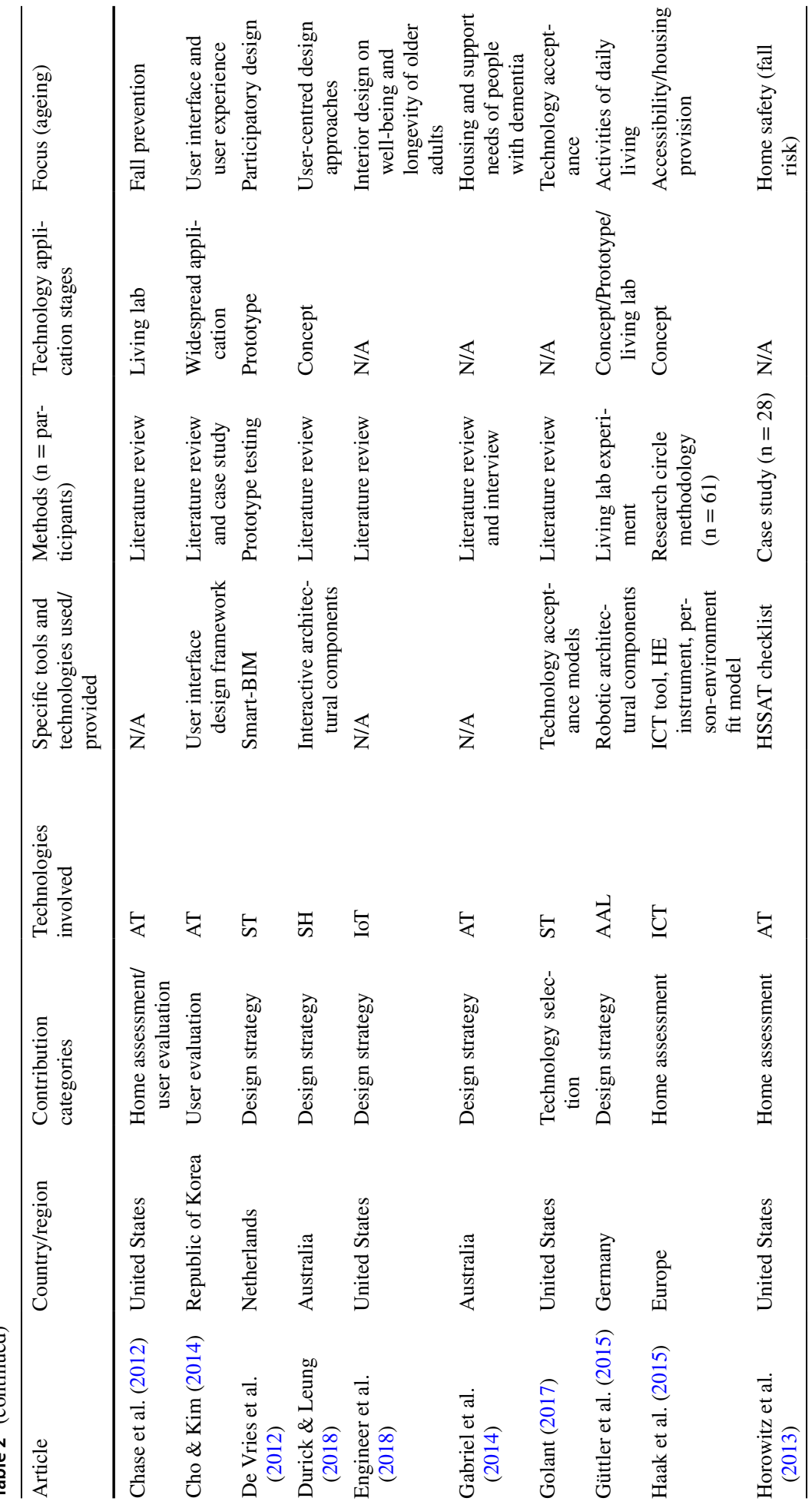




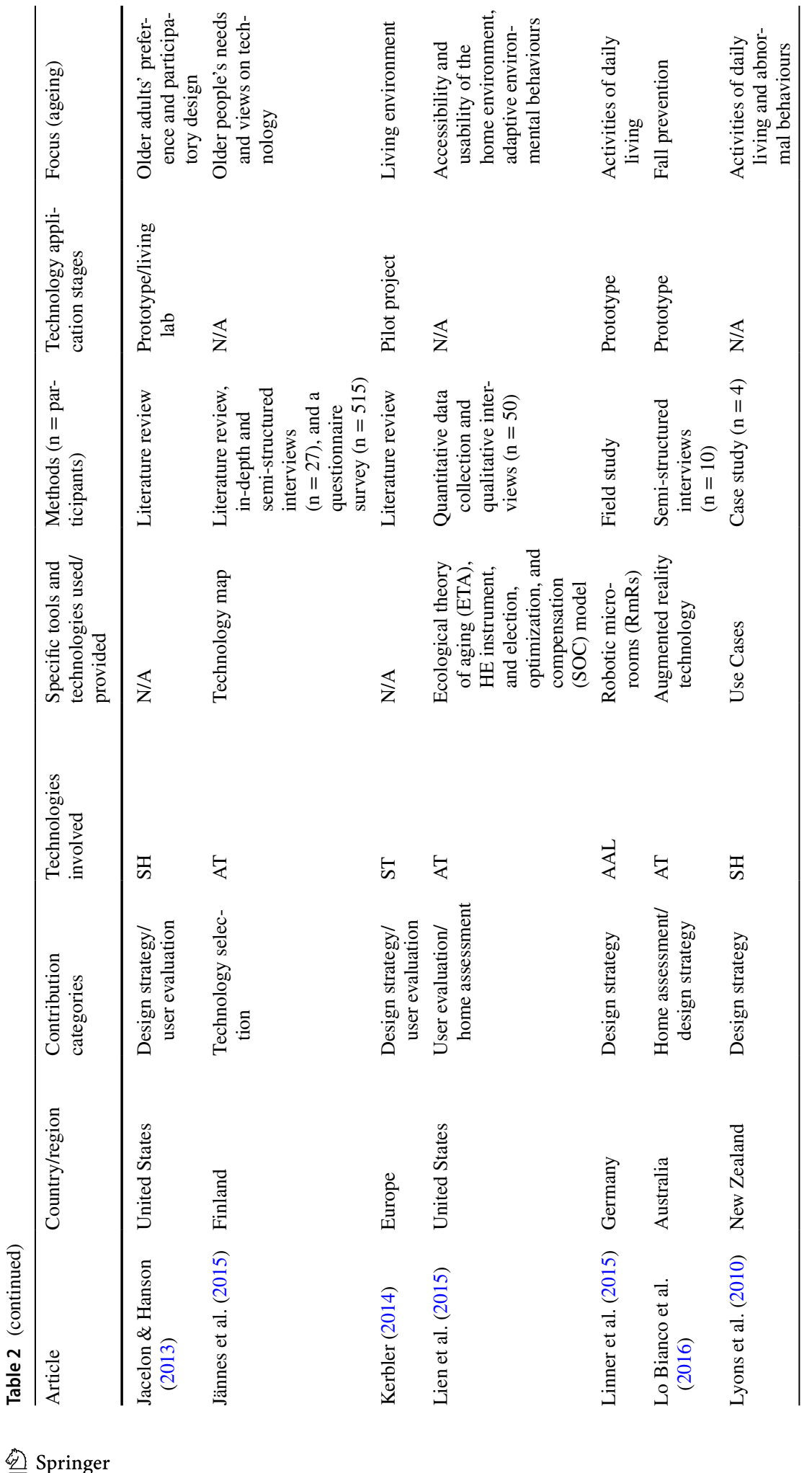




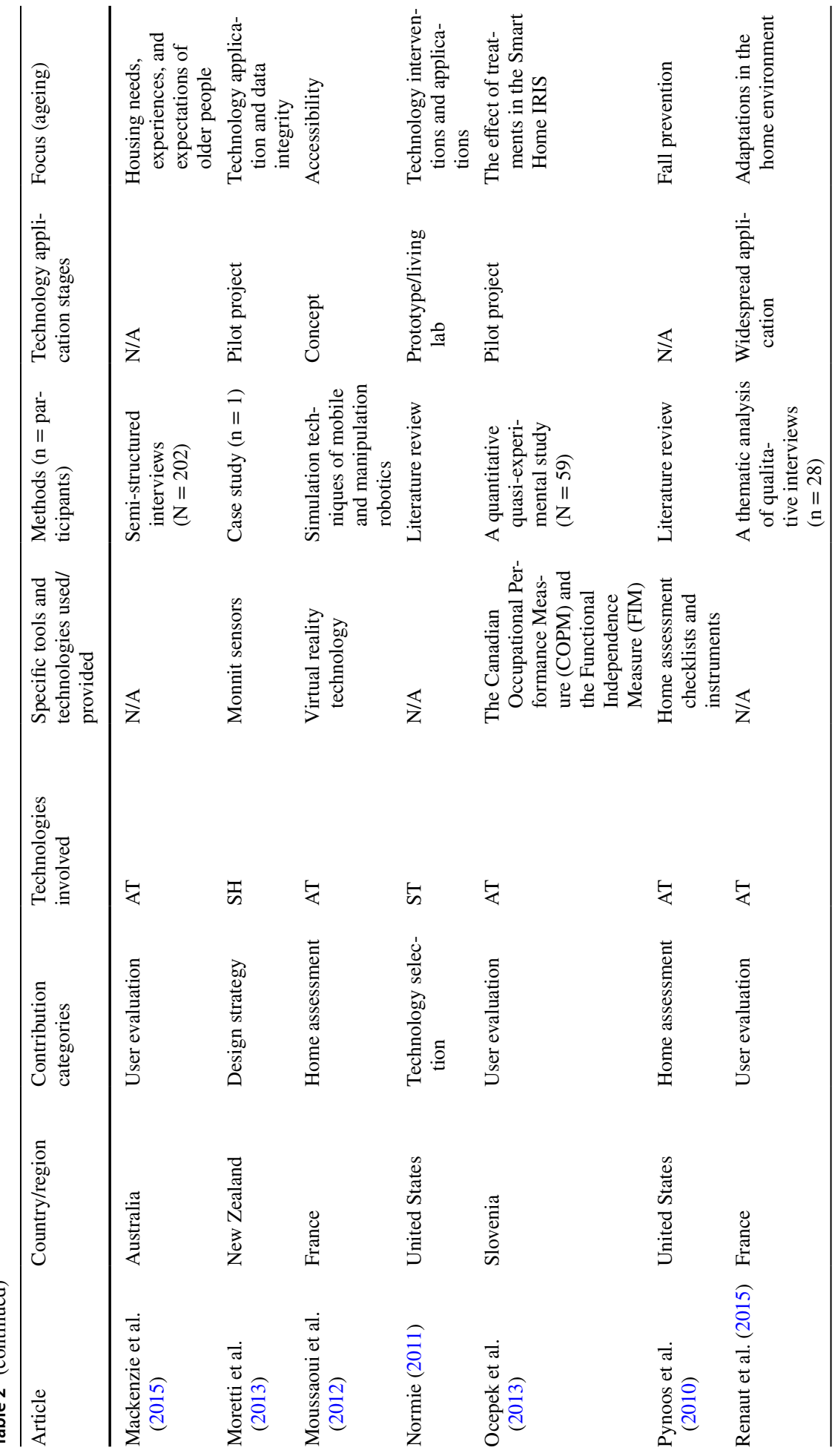




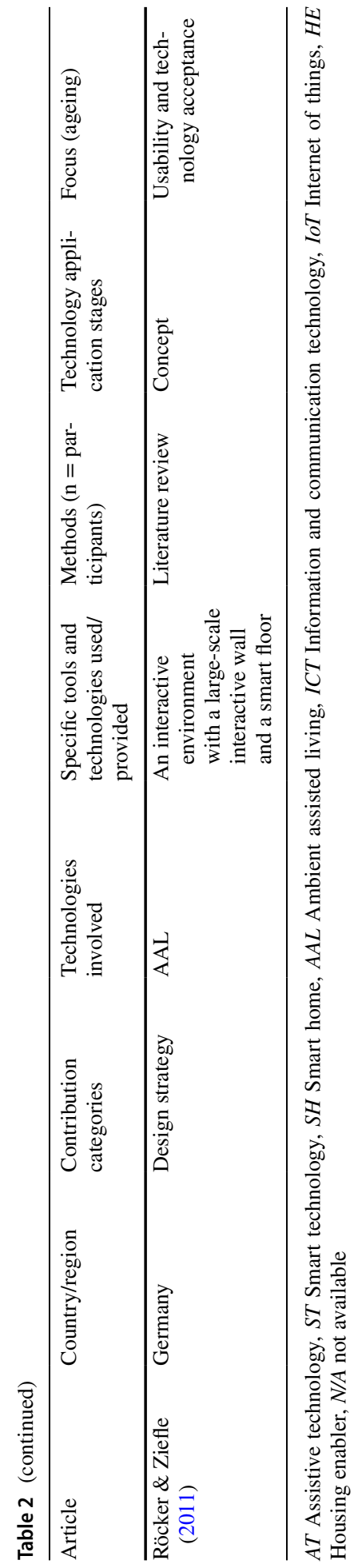

글 Springer 
Open Access This article is licensed under a Creative Commons Attribution 4.0 International License, which permits use, sharing, adaptation, distribution and reproduction in any medium or format, as long as you give appropriate credit to the original author(s) and the source, provide a link to the Creative Commons licence, and indicate if changes were made. The images or other third party material in this article are included in the article's Creative Commons licence, unless indicated otherwise in a credit line to the material. If material is not included in the article's Creative Commons licence and your intended use is not permitted by statutory regulation or exceeds the permitted use, you will need to obtain permission directly from the copyright holder. To view a copy of this licence, visit http://creativecommons.org/licenses/by/4.0/.

\section{References}

Agree, E. M. (2014). The potential for technology to enhance independence for those aging with a disability. Disability and Health Journal, 7(1 SUPPL), S33-S39. https://doi.org/10.1016/j.dhjo.2013.09.004

Ahrentzen, S., \& Tural, E. (2015). The role of building design and interiors in ageing actively at home. Building Research and Information, 43(5), 582-601. https://doi.org/10.1080/09613218.2015.1056336

Allameh, E., Jozam, M.H., Vries, B.D., Timmermans, H., \& Masoud, M. (2013). Smart Homes from vision to reality: eliciting users' preferences of Smart Homes by a virtual experimental method.

Arthanat, S., Wilcox, J., \& Macuch, M. (2019). Profiles and predictors of smart home technology adoption by older adults. OTJR Occupation, Participation and Health. https://doi.org/10.1177/1539449218 813906

Azimi, I., Rahmani, A. M., Liljeberg, P., \& Tenhunen, H. (2017). Internet of things for remote elderly monitoring: A study from user-centered perspective. Journal of Ambient Intelligence and Humanized Computing, 8(2), 273-289. https://doi.org/10.1007/s12652-016-0387-y

Bamzar, R. (2019). Assessing the quality of the indoor environment of senior housing for a better mobility: A Swedish case study. Journal of Housing and the Built Environment. https://doi.org/10.1007/ s10901-018-9623-4

Beech, B. R., and Roberts, D. (2008). Assistive technology and older people. SCIE Research Briefing, 28(August), 1-12. Retrieved from http://www.scie.org.uk/publications/briefings/briefing28/

Behr, R., Sciegaj, M., Walters, R., Bertoty, J., \& Dungan, R. (2010). Addressing the housing challenges of an aging population: initiatives by blueroof technologies in McKeesport Pennsylvania. Journal of Architectural Engineering, 17(4), 162-169. https://doi.org/10.1061/(asce)ae.1943-5568.0000033

Bishop, M., Dennis, K. L., Bishop, L. A., Sheppard-Jones, K., Bishop, F., \& Frain, M. (2015). The prevalence and nature of modified housing and assistive devices use among Americans with multiple sclerosis. Journal of Vocational Rehabilitation, 42(2), 153-165. https://doi.org/10.3233/JVR-150732

Bitterman, N., \& Shach-Pinsly, D. (2015). Smart home - A challenge for architects and designers. Architectural Science Review, 58(3), 266-274. https://doi.org/10.1080/00038628.2015.1034649

Bouchard, K., Bouchard, B., and Bouzouane, A. (2014). Practical Guidelines to Build Smart Homes: Lessons Learned.

Braubach, M., \& Power, A. (2011). Housing conditions and risk: Reporting on a European study of housing quality and risk of accidents for older people. Journal of Housing for the Elderly, 25(3), 288-305. https://doi.org/10.1080/02763893.2011.595615

Carnemolla, P. (2018). Ageing in place and the internet of things - how smart home technologies, the built environment and caregiving intersect. Visualization in Engineering. https://doi.org/10.1186/ s40327-018-0066-5

Carnemolla, P., \& Bridge, C. (2020). A scoping review of home modification interventions - Mapping the evidence base. Indoor and Built Environment, 29(3), 299-310. https://doi.org/10.1177/1420326X18 761112

Carter, S. E., Campbell, E. M., Sanson-Fisher, R. W., \& Gillespie, W. J. (2000). Accidents in older people living at home: A community-based study assessing prevalence, type, location and injuries. Australian and New Zealand Journal of Public Health, 24(6), 633-636. https://doi.org/10.1111/j.1467-842X. 2000.tb00532.x

Chabot, M., Delaware, L., McCarley, S., Little, C., Nye, A., \& Anderson, E. (2019). Living in place: The impact of smart technology. Current Geriatrics Reports. https://doi.org/10.1007/s13670-019-00296-4

Chase, C. A., Mann, K., Wasek, S., \& Arbesman, M. (2012). Systematic review of the effect of home modification and fall prevention programs on falls and the performance of community-dwelling older adults. American Journal of Occupational Therapy, 66(3), 284-291. https://doi.org/10.5014/ajot.2012.005017 
Cho, M. E., \& Kim, M. J. (2014). Characterizing the interaction design in healthy smart home devices for the elderly. Indoor and Built Environment, 23(1), 141-149. https://doi.org/10.1177/14203 26X14521229

Cho, H. Y., MacLachlan, M., Clarke, M., \& Mannan, H. (2016). Accessible home environments for people with functional limitations: A systematic review. International Journal of Environmental Research and Public Health. https://doi.org/10.3390/ijerph13080826

de Klerk, M., Verbeek-Oudijk, D., Plaisier, I., and den Draak, M. (2019). Zorgen voor thuiswonende ouderen, 103.

De Vries, B., Allameh, E., and Heidari Jozam, M. (2012). Smart-BIM (Building Information Modeling). 2012 Proceedings of the 29th International Symposium of Automation and Robotics in Construction, ISARC 2012, (June). doi: https://doi.org/10.4017/gt.2012.11.02.044.00

Demiris, G., Skubic, M., Rantz, M. J., Courtney, K. L., Aud, M. A., Tyrer, H. W., \& Lee, J. (2006). Facilitating interdisciplinary design specification of "smart" homes for aging in place. Studies in Health Technology and Informatics, 124, 45-50.

Dewsbury, G., Rouncefield, M., Clarke, K., \& Sommerville, I. (2004). Depending on digital design: Extending inclusivity. Housing Studies., 19(5), 811-825. https://doi.org/10.1080/0267303042 000249224

Ding, D., Cooper, R. A., Pasquina, P. F., \& Fici-pasquina, L. (2011). Maturitas Sensor technology for smart homes. Maturitas, 69(2), 131-136. https://doi.org/10.1016/j.maturitas.2011.03.016

Durick, J., \& Leung, L. (2018). Designing augmented, domestic environments to support ageing in place. In J. Huber, R. Shilkrot, P. Maes, \& S. Nanayakkara (Eds.), Assistive Augmentation (pp. 117-129). Singapore: Springer Singapore. https://doi.org/10.1007/978-981-10-6404-3_7

Engineer, A., Sternberg, E. M., \& Najafi, B. (2018). Designing interiors to mitigate physical and cognitive deficits related to aging and to promote longevity in older adults: A review. Gerontology, 85721, 612-622. https://doi.org/10.1159/000491488

Frisardi, V., \& Imbimbo, B. P. (2011). Gerontechnology for demented patients: Smart homes for smart aging. Journal of Alzheimer's Disease, 23(1), 143-146. https://doi.org/10.3233/JAD-2010-101599

Gabriel, M., Stirling, C., Faulkner, D., \& Lloyd, B. (2014). Future housing and support needs of people with dementia, AHURI Positioning Paper No. 159, Australian Housing and Urban Research Institute Limited, Melbourne, https://www.ahuri.edu.au/research/position-papers/159

Gibson, G., Dickinson, C., Brittain, K., \& Robinson, L. (2015). The everyday use of assistive technology by people with dementia and their family carers: A qualitative study. BMC Geriatrics. https://doi. org/10.1186/s12877-015-0091-3

Gobbens, R. J. J., \& Van Assen, M. A. L. M. (2018). Associations of environmental factors with quality of life in older adults. The Gerontologist, 58(1), 101-110. https://doi.org/10.1093/geront/gnx051

Golant, S. M. (2017). A theoretical model to explain the smart technology adoption behaviors of elder consumers (Elderadopt). Journal of Aging Studies, 42(August), 56-73. https://doi.org/10.1016/j. jaging.2017.07.003

Grgurić, A., Mošmondor, M., \& Huljenić, D. (2019). The smarthabits: An intelligent privacy-aware home care assistance system. Sensors. https://doi.org/10.3390/s19040907

Güttler, J., Georgoulas, C., Linner, T., \& Bock, T. (2015). Towards a future robotic home environment: A survey. Gerontology, 61(3), 268-280. https://doi.org/10.1159/000363698

Haak, M., Slaug, B., Oswald, F., Schmidt, S. M., Rimland, J. M., Tomsone, S., \& Iwarsson, S. (2015). Cross-national user priorities for housing provision and accessibility - Findings from the european innovage project. International Journal of Environmental Research and Public Health, 12(3), 2670-2686. https://doi.org/10.3390/ijerph120302670

Hammink, C., Moor, N., \& Mohammadi, M. (2019). A systematic literature review of persuasive architectural interventions for stimulating health behaviour. Facilities, 37(11-12), 743-761. https://doi. org/10.1108/F-07-2017-0065

Heart, T., \& Kalderon, E. (2013). Older adults: Are they ready to adopt health-related ICT? International Journal of Medical Informatics, 82(11), e209-e231. https://doi.org/10.1016/j.ijmedinf.2011.03.002

Helal, S., \& Bull, C. N. (2019). From smart homes to smart-ready homes and communities. Dementia and Geriatric Cognitive Disorders. https://doi.org/10.1159/000497803

Helal, S., Chen, C., Kim, E., Bose, R., \& Lee, C. (2012). Toward an ecosystem for developing and programming assistive environments. Proceedings of the IEEE, 100(8), 2489-2504. https://doi.org/10. 1109/JPROC.2012.2200548

Horowitz, B. P., Nochajski, S. M., \& Schweitzer, J. A. (2013). Occupational therapy community practice and home assessments: Use of the home safety self-assessment tool (HSSAT) to support aging in place. Occup Ther Health Care. https://doi.org/10.3109/07380577 
Hui, T. K. L., Sherratt, R. S., \& Sánchez, D. D. (2017). Major requirements for building Smart Homes in Smart Cities based on Internet of Things technologies. Future Generation Computer Systems, 76, 358-369. https://doi.org/10.1016/j.future.2016.10.026

Iwarsson, S. (2015). Housing adaptations and home modifications. International Handbook of Occupational Therapy Interventions, Second Edition. https://doi.org/10.1007/978-3-319-08141-0

Jacelon, C. S., \& Hanson, A. (2013). Older adults' participation in the development of smart environments: An integrated review of the literature. Geriatric Nursing, 34(2), 116-121. https://doi.org/10.1016/j. gerinurse.2012.11.001

Jännes, J., Hämäläinen, P., Hanski, J., \& Lanne, M. (2015). Homelike living for elderly people: A needsbased selection of technological solutions. Home Health Care Management and Practice, 27(2), 64-72. https://doi.org/10.1177/1084822314543798

Jaouhari, S. E. L., Palacios-Garcia, E. J., Anvari-Moghaddam, A., \& Bouabdallah, A. (2019). Integrated management of energy, wellbeing and health in the next generation of smart homes. Sensors (switzerland), 19(3), 1-24. https://doi.org/10.3390/s19030481

Kasugai, K., Ziefle, M., Röcker, C., and Russell, P. (2010). Creating Spatio-Temporal Contiguities Between Real and Virtual Rooms in an Assistive Living Environment. doi: https://doi.org/10.14236/ewic/creat e2010.8

Kerbler, B. (2014). An innovative built environment form for dwellings for the elderly. Metu Journal of the Faculty of Architecture, 31(1), 119-137. https://doi.org/10.4305/METU.JFA.2014.1.6

Kim, M. J., Oh, M. W., Cho, M. E., Lee, H., \& Kim, J. T. (2013). A critical review of user studies on healthy smart homes. Indoor and Built Environment, 22(1), 260-270. https://doi.org/10.1177/1420326X12 469733

Konstantinidis, E. I., Bamparopoulos, G., Billis, A., \& Bamidis, P. D. (2015). Internet of things for an agefriendly healthcare. Studies in Health Technology and Informatics, 210, 587-591. https://doi.org/10. 3233/978-1-61499-512-8-587

Kwok, J., Wong, W., \& Leung, J. K. L. (2016). Modelling factors influencing the adoption of smart-home technologies. Facilities, 34(13/14), 906-923. https://doi.org/10.1108/F-05-2016-0048

Labonnote, N., \& Høyland, K. (2017). Smart home technologies that support independent living: Challenges and opportunities for the building industry - a systematic mapping study. Intelligent Buildings International, 91, 40-63. https://doi.org/10.1080/17508975.2015.1048767

Lamb, S. E., Jørstad-Stein, E. C., Hauer, K., \& Becker, C. (2005). Development of a common outcome data set for fall injury prevention trials: The prevention of falls network Europe consensus. Journal of the American Geriatrics Society, 53(9), 1618-1622. https://doi.org/10.1111/j.1532-5415.2005.53455.x

Lê, Q., Nguyen, H. B., \& Barnett, T. (2012). Smart homes for older people: Positive aging in a digital world. Future Internet, 4(2), 607-617. https://doi.org/10.3390/fi4020607

Lee, L. N., \& Kim, M. J. (2020). A critical review of smart residential environments for older adults with a focus on pleasurable experience. Frontiers in Psychology, 10(January), 1-15. https://doi.org/10.3389/ fpsyg.2019.03080

Leidelmeijer, K. (2017). Monitor Investeren in de toekomst. Retrieved from https://www.rigo.nl/

Li, R., Lu, B., \& McDonald-Maier, K. D. (2015). Cognitive assisted living ambient system: A survey. Digital Communications and Networks, 1(4), 229-252. https://doi.org/10.1016/j.dcan.2015.10.003

Lien, L. L., Steggell, C. D., \& Iwarsson, S. (2015). Adaptive strategies and person-environment fit among functionally limited older adults aging in place: A mixed methods approach. International Journal of Environmental Research and Public Health, 12(9), 11954-11974. https://doi.org/10.3390/ijerph1209 11954

Linner, T., Georgoulas, C., and Bock, T. (2012). Advanced building engineering: Deploying mechatronics and robotics in architecture. 2012 Proceedings of the 29th International Symposium of Automation and Robotics in Construction, ISARC 2012, (November 2017). doi: https://doi.org/10.4017/gt.2012.11.02. 158.711

Linner, T., Güttler, J., Bock, T., \& Georgoulas, C. (2015). Assistive robotic micro-rooms for independent living. Automation in Construction., 51, 8-22. https://doi.org/10.1016/j.autcon.2014.12.013

Liu, L., Stroulia, E., Nikolaidis, I., Miguel-Cruz, A., \& Rios Rincon, A. (2016). Smart homes and home health monitoring technologies for older adults: A systematic review. International Journal of Medical Informatics, 91, 44-59. https://doi.org/10.1016/j.ijmedinf.2016.04.007

Lo Bianco, M., Pedell, S., Renda, G., \& Kapoor, A. (2015). HCI methods for empowering discussion on person-centered fall prevention with older adults. In Proceedings of the Annual Meeting of the Australian Special Interest Group for ComputerHuman Interaction (pp. 255-263). New York, NY, USA: Association for Computing Machinery. https://doi.org/10.1145/2838739.2838767

Lo Bianco, M., Pedell, S., and Renda, G. (2016). Augmented reality and home modifications: A tool to empower older adults in fall prevention. In Proceedings of the 28th Australian Conference on 
Computer-Human Interaction (pp. 499-507). New York,NY, USA: Association for Computing Machinery. https://doi.org/10.1145/3010915.3010929

Lyons, P., Cong, A. T., Steinhauer, H. J., Marsland, S., Dietrich, J., \& Guesgen, H. W. (2010). Exploring the responsibilities of single-inhabitant smart homes with use cases. Journal of Ambient Intelligence and Smart Environments, 2(3), 211-232. https://doi.org/10.3233/AIS-2010-0076

Mackenzie, L., Curryer, C., \& Byles, J. E. (2015). Narratives of home and place: Findings from the housing and independent living study. Ageing and Society, 35(8), 1684-1712. https://doi.org/10.1017/S0144 $686 \times 14000476$

Marikyan, D., Papagiannidis, S., \& Alamanos, E. (2019). A systematic review of the smart home literature: A user perspective. Technological Forecasting and Social Change., 138, 139-154. https://doi. org/10.1016/j.techfore.2018.08.015

McCreadie, C., \& Tinker, A. (2005). The acceptability of assistive technology to older people. Ageing and Society, 25(1), 91-110. https://doi.org/10.1017/S0144686X0400248X

Mohammadi, M. (2008). Automated assisted homes for the elderly. I-CREATe 2008 - International Convention on Rehabilitation Engineering and Assistive Technology 2008, (May 2008), 266-270.

Mohammadi, M. (2010). Empowering Seniors through domotics homes: Integrating intelligent technology in senior citizen ' home by the perspectives of demand and supply. Technische Universiteit Eindhoven. https://doi.org/10.6100/IR674707

Moretti, G., Marsland, S., Basu, D., \& Sen Gupta, G. (2013). Towards a monitoring smart home for the elderly: One experience in retrofitting a sensor network into an existing home. Journal of Ambient Intelligence and Smart Environments, 5(6), 639-656. https://doi.org/10.3233/AIS-130233

Morris, M. E., Adair, B., Ozanne, E., Kurowski, W., Miller, K. J., Pearce, A. J., \& Said, C. M. (2014). Smart technologies to enhance social connectedness in older people who live at home. Australasian Journal on Ageing, 33(3), 142-152. https://doi.org/10.1111/ajag.12154

Moussaoui, A., Pruski, A., \& Maaoui, C. (2012). Virtual reality for accessibility assessment of a built environment for a wheelchair user. Technology and Disability, 24(2), 129-137. https://doi.org/10. 3233/TAD-2012-0341

Ni, Q., Hernando, A. B. G., \& de la Cruz, I. P. (2015). The elderly's independent living in smart homes: A characterization of activities and sensing infrastructure survey to facilitate services development. Sensors. https://doi.org/10.3390/s150511312

Normie, L. (2011). Technology for ageing in place. Global Ageing: Issues \& Action, 7(2), 45-53.

Ocepek, J., Roberts, A. E. K., \& Vidmar, G. (2013). Evaluation of treatment in the smart home IRIS in terms of functional independence and occupational performance and satisfaction. Computational and Mathematical Methods in Medicine. https://doi.org/10.1155/2013/926858

OECD. (2013). The Netherlands Highlights from A Good Life in Old Age? Monitoring and Improving Quality in Long-Term Care, OECD Publishing, 2013. Retrieved from https://www.oecd.org/els/ health-systems/Netherlands-OECD-EC-Good-Time-in-Old-Age.pdf

Pal, D., Triyason, T., and Funikul, S. (2017). Smart Homes and Quality of Life for the Elderly: A Systematic Review. Proceedings - 2017 IEEE International Symposium on Multimedia, ISM 2017, 2017-Janua(August 2018), 413-419. doi: https://doi.org/10.1109/ISM.2017.83

Peruzzini, M., \& Germani, M. (2016). Design of a service-oriented architecture for AAL. International Journal of Agile Systems and Management, 9(2), 154-178. https://doi.org/10.1504/IJASM.2016. 078582

Phan, L. A., \& Kim, T. (2020). Breaking down the compatibility problem in smart homes: A dynamically updatable gateway platform. Sensors. https://doi.org/10.3390/s20102783

Pynoos, J., Steinman, B. A., \& Nguyen, A. Q. D. (2010). Environmental assessment and modification as fall-prevention strategies for older adults. Physiology and Behavior. https://doi.org/10.1016/j.physb eh.2017.03.040

Rafferty, J., Nugent, C. D., Liu, J., \& Chen, L. (2017). From activity recognition to intention recognition for assisted living within smart homes. IEEE Transactions on Human-Machine Systems, 47(3), 368-379. https://doi.org/10.1109/THMS.2016.2641388

Ravishankar, V. K., Burleson, W., \& Mahoney, D. (2015). Smart home strategies for user-centered functional assessment of older adults. International Journal of Automation and Smart Technology, 5(4), 233-242. https://doi.org/10.5875/ausmt.v5i4.952

Remillard, E. T., Fausset, C. B., \& Fain, W. B. (2019). Aging with long-term mobility impairment: Maintaining activities of daily living via selection, optimization, and compensation. The Gerontologist, 59(3), 559-569. https://doi.org/10.1093/geront/gnx186

Renaut, S., Ogg, J., Petite, S., \& Chamahian, A. (2015). Home environments and adaptations in the context of ageing. Ageing and Society, 35(6), 1278-1303. https://doi.org/10.1017/S0144686X140002 21 
Reeder, B., Meyer, E., Lazar, A., Chaudhuri, S., Thompson, H. J., \& Demiris, G. (2013). Framing the evidence for health smart homes and home-based consumer health technologies as a public health intervention for independent aging: A systematic review. International Journal of Medical Informatics, 82(7), 565-579. https://doi.org/10.1016/j.ijmedinf.2013.03.007

Rieh, S.-Y. (2018). Post-occupancy evaluation of urban public housing in Korea: Focus on experience of elderly females in the ageing society. Indoor and Built Environment, 29(3), 372-388. https://doi. org/10.1177/1420326X18782578

Robillard, J. M., Li, A. W., Jacob, S., Wang, D., Zou, X., \& Hoey, J. (2017). Co-creating emotionally aligned smart homes using social psychological modeling. ACM International Conference Proceeding Series. https://doi.org/10.1145/31342303134242

Röcker, C., \& Ziefle, M. (2011). E-Health, assistive technologies and applications for assisted living: Challenges and solutions. IGI Global. https://doi.org/10.4018/978-1-60960-469-1

Schikhof, Y., Mulder, I., \& Choenni, S. (2010). Who will watch (over) me? Humane monitoring in dementia care. International Journal of Human Computer Studies, 68(6), 410-422. https://doi.org/10.1016/j. ijhcs.2010.02.002

Storey, K. (2011). Smart houses and smart technology: Overview and implications for independent living and supported living services. Intellectual and Developmental Disabilities, 49(1), 50-55. https://doi. org/10.1352/1934-9556-49.1.50

Thomése, F., \& Broese van Groenou, M. (2006). Adaptive strategies after health decline in later life: Increasing the person-environment fit by adjusting the social and physical environment. European Journal of Ageing, 3(4), 169-177. https://doi.org/10.1007/s10433-006-0038-9

Trecartin, S. M., \& Cummings, S. M. (2018). Systematic review of the physical home environment and the relationship to psychological well-being among community-dwelling older adults. Journal of Gerontological Social Work. https://doi.org/10.1080/01634372.2018.1463339

Uddin, M. Z., Khaksar, W., \& Torresen, J. (2018). Ambient sensors for elderly care and independent living: A survey. Sensors (switzerland), 18(7), 1-31. https://doi.org/10.3390/s18072027

Udupa, P., \& Yellampalli, S. S. (2018). Smart home for elder care using wireless sensor. Circuit World, 44(2), 69-77. https://doi.org/10.1108/CW-12-2017-0072

United Nations. (2019). World Population Ageing 2019: Highlights. Department of Economic and Social Affairs, Population Division (2019). doi: https://doi.org/10.5860/choice.40-1307

van Buuren, L. P. G., Mohammadi, M., and Guerra Santin, O. (2019). Evaluating Three Validation-Methods for an Architectural Intervention for Seniors with Dementia in the Empathic Design Framework, a Case Study. In R. Brankaert \& W. IJsselsteijn (Eds.), Dementia Lab 2019. Making Design Work: Engaging with Dementia in Context - 4th Conference, D-Lab 2019, Proceedings (pp. 24-34). (Communications in Computer and Information Science; Vol. 1117). Springer. doi: https://doi.org/10.1007/ 978-3-030-33540-3_3

Van Steenwinkel, I., Dierckx de Casterlé, B., \& Heylighen, A. (2017). How architectural design affords experiences of freedom in residential care for older people. Journal of Aging Studies, 41(March), 84-92. https://doi.org/10.1016/j.jaging.2017.05.001

Visutsak, P., and Daoudi, M. (2017). The smart home for the elderly: Perceptions, technologies and psychological accessibilities: The requirements analysis for the elderly in Thailand. ICAT 2017 - 26 th International Conference on Information, Communication and Automation Technologies, Proceedings, 2017Decem, 1-6. doi: https://doi.org/10.1109/ICAT.2017.8171625

Wang, S., Bolling, K., Mao, W., Reichstadt, J., Jeste, D., Kim, H.-C., \& Nebeker, C. (2019). Technology to support aging in place: Older adults' perspectives. Healthcare. https://doi.org/10.3390/healthcare 7020060

Wong, J. K. W., Leung, J., Skitmore, M., \& Buys, L. (2017). Technical requirements of age-friendly smart home technologies in high-rise residential buildings: A system intelligence analytical approach. Automation in Construction, 73, 12-19. https://doi.org/10.1016/j.autcon.2016.10.007

Publisher's Note Springer Nature remains neutral with regard to jurisdictional claims in published maps and institutional affiliations. 